\title{
High-resolution Rayleigh wave phase velocity maps from ambient noise tomography in North China*
}

\author{
Jiatie Pan* \\ Institute of Geophysics, China Earthquake Administration, Beijing 100081, China
}

\begin{abstract}
We presented high-resolution Rayleigh wave phase velocity maps at periods ranging from $5 \mathrm{~s}$ to $30 \mathrm{~s}$ in the northeast part of the North China Craton (NNCC). Continuous time-series of vertical component between October 2006 and December 2008, recorded by 187 broadband stations temporarily deployed in the NNCC region, have been cross-correlated to obtain estimated fundamental mode Rayleigh wave Green's functions. Using the frequency and time analysis technique based on continuous wavelet transformation, we measured 3667 Rayleigh wave phase velocity dispersion curves. High-resolution phase velocity maps at periods of 5, 10, 20 and $30 \mathrm{~s}$ were reconstructed with grid size $0.25^{\circ} \times 0.25^{\circ}$, which reveal lateral heterogeneity of shear wave structure in the crust and upper mantle of NNCC. For periods shorter than $10 \mathrm{~s}$, the phase velocity variations are well correlated with the principal geological units in the NNCC, with low-speed anomalies corresponding to the major sedimentary basins and high-speed anomalies coinciding with the main mountain ranges. Within the period range from $20 \mathrm{~s}$ to $30 \mathrm{~s}$, high phase velocity observed in eastern NCC is coincident with the thin crust, whereas low phase velocities imaged in central NCC is correlated to the thick crust. However, the low-velocity anomaly in the Beijing-TianjinTangshan region displayed in the $20 \mathrm{~s}$ and $30 \mathrm{~s}$ phase maps may be associated with fluids.
\end{abstract}

Key words: Rayleigh wave; phase velocity; ambient noise tomography; wavelet transformation; North China Craton

CLC number: P315.3 Document code: A

\section{Introduction}

The North China Craton (NCC) is the largest and oldest known cratonic block in the Chinese mainland, and it is unique for its unusual Phanerozoic tectonic activity. It has experienced a wide range of tectonic alterations since Mesozoic, evidenced by geological phenomenon such as the wide range of intrusion and eruption of igneous rocks, a large number of strong earthquakes that have happened in the area, (Griffin et al., 1998; Menzies and Xu, 1998; Xu et al., 2001). A lot of geological and geophysical studies showed that it may have significantly different lithosphere/asthenosphere structures among each part of the NCC (e.g., Zhao et

\footnotetext{
* Received 24 April 2012; accepted in revised form 2 June 2012; published 10 June 2012.

† Corresponding author. e-mail: panj15I@gmail.com

(c) The Seismological Society of China, Institute of Geophysics,

China Earthquake Administration, and Springer-Verlag Berlin Heidelberg 2012
}

al., 2000, 2005; Jia and Zhang, 2005; He et al., 2009; Huang et al., 2009; Li et al., 2009; Fang et al., 2010). Therefore, the NCC can be considered as a natural laboratory for studying the formation and evolution of continental lithosphere. For this reason, it is highly relevant to study the structure of crust and mantle in the NC$\mathrm{C}$ for obtaining information on the tectonic alteration underwent by the NCC and the earthquake activity.

Here we focus on the region, located in the northeast part of the $\mathrm{NCC}\left(\mathrm{NNCC}, 37^{\circ} \mathrm{N}-42^{\circ} \mathrm{N}\right.$, $\left.111^{\circ} \mathrm{E}-120^{\circ} \mathrm{E}\right)$, that mainly comprise of the North China Basin (NCB) and the Yanshan-Taihang Mountain$\mathrm{s}$, the two major tectonic units locate in the eastern and the central NCC (Figure 1), respectively. The western part of the study region is occupied by the Taihangshan uplift region with some small intermountain basins (e.g., Datong basin, Zhangjiakou basin, YanqingHuailai basin etc.). The northeastern part of the study area is dominated by the relatively stable Yanshan uplift 
with its major tectonic units oriented in the E-W direction. In the eastern NNCC it is mainly covered by NCB where many subtectonic units (e.g., uplifts and depressions in basins) developed. In the study region NCB can be divided into one internal uplift (Cangzhou) and two depressions (Jizhong, Huanghua) (Chang, 1991). The eastern and central part of the NCC underwent distinctive evolutions during the Late Mesozoic and Cenozoic. In contrast to the Ordos block located in western part of NCC, which seems to have preserved the typical features of a stable craton, the eastern NCC has experienced significant lithospheric thinning as evidenced by widespread magmatism activity and normal faulting, among other manifestations. The eastern part of the NCC is also one of the most seismically active intracontinental regions in the world.

Global and regional tomographic studies have revealed a pronounced low-velocity anomaly at the 100 $\mathrm{km}$ depth beneath the NCC and related the low velocities to the widespread Cenozoic rifting and magmatism (e.g., Huang et al., 2009; An et al., 2009). However, these tomographic images do not have sufficient resolution to interpret the differences of upper mantle structure among different blocks of NCC. Being proved to have good resolution, ambient noise tomography (ANT) are considered to be a very powerful way to study the crustal and upper mantle structure of the Earth (e.g., Shapiro et al., 2005; Sabra et al., 2005; Lin et al., 2007; Yang et al., 2007; Zheng et al., 2008, 2011; Zhou et al., 2012). Additionally, North China Seismic Array (NCSA) stations deployed around the NNCC (e.g., He et al., 2009; Fang et al., 2010; Pan et al., 2011) allow us to explore the crust and upper mantle structure at a more detailed level by ANT method. He et al. (2009) and Pan et al. (2011) obtained Rayleigh wave phase velocity maps between 10-60 s using teleseismic observations recorded by NCSA stations, and their results made a good agreement with each other, suggesting that phase velocities are faster in the central NCC than that in the eastern NCC at shorter periods (e.g., $\sim 16 \mathrm{~s}$ ), and it becomes a contrary situation at longer periods (e.g., $26 \mathrm{~s}, 30 \mathrm{~s}$ ). Moreover, the lateral variations of phase velocities between central NCC and eastern NCC block become smaller at much longer periods (e.g., 60 s). Fang et al. (2010) have made use of ambient seismic noise measurements from NCSA stations to generate Rayleigh wave group velocity maps at periods from 4.5 to $40 \mathrm{~s}$ with a resolution of $25 \mathrm{~km}$. However, these resulting maps for Rayleigh wave group and phase velocities, respectively obtained from ambient noise tomography (e.g., Fang et al., 2010) and classical surface wave tomography (CSWT) (e.g., He et al., 2009; Pan et al., 2011), are not consistent with each other and even contradict, especially as the period becomes longer (e.g., between $20-30 \mathrm{~s}$ ).

In this study, we applied ANT to the data that have recorded continuously from the NCSA between October 2006 and September 2008 to construct highresolution Rayleigh wave phase velocity maps in this region. We then compared the obtained maps with previous tomography (Pan et al., 2011; He et al., 2009; Fang et al., 2010). We believe that the shorter periods and more detailed phase velocity images presented in this paper would be a significant improvement over published dispersion results and shed new light on geological structure and tectonic process of this region.

\section{Data}

In order to investigate the deep detailed structure of the NCC, the NCSA was carried out by the Institute of Geophysics, China Earthquake Administration from October 2006 to April 2009. 250 transportable stations were deployed in the northeast part of the North China, of which 190 were broadband stations. Each station was equipped with Guralp CMG-3ESPC sensor (frequency bandwith $0.02-60 \mathrm{~s}$ ) and recorder of Refteck130B. Time of the instrument was synchronized with GPS. In this study we collected the vertical component of continuous seismic data recorded by 187 broadband stations of NCSA from October 2006 to December 2008. Figure 1 shows the distribution of those stations used in this study superimposed on a simplified map of the main tectonic features of NNCC. The data over 26 months helps to make the distribution of noise sources more homogeneous, allowing more reliable tomographic results can be obtained. These continuous recordings have been cross-correlated and stacked for all station pairs. Path lengths range from $100 \mathrm{~km}$ to more than $600 \mathrm{~km}$. The distribution of inter-station paths provides very dense and homogeneous ray path coverage for NNCC, allowing a significant increase in resolution with respect to previous studies (Sheng et al., 2008, 2011). 


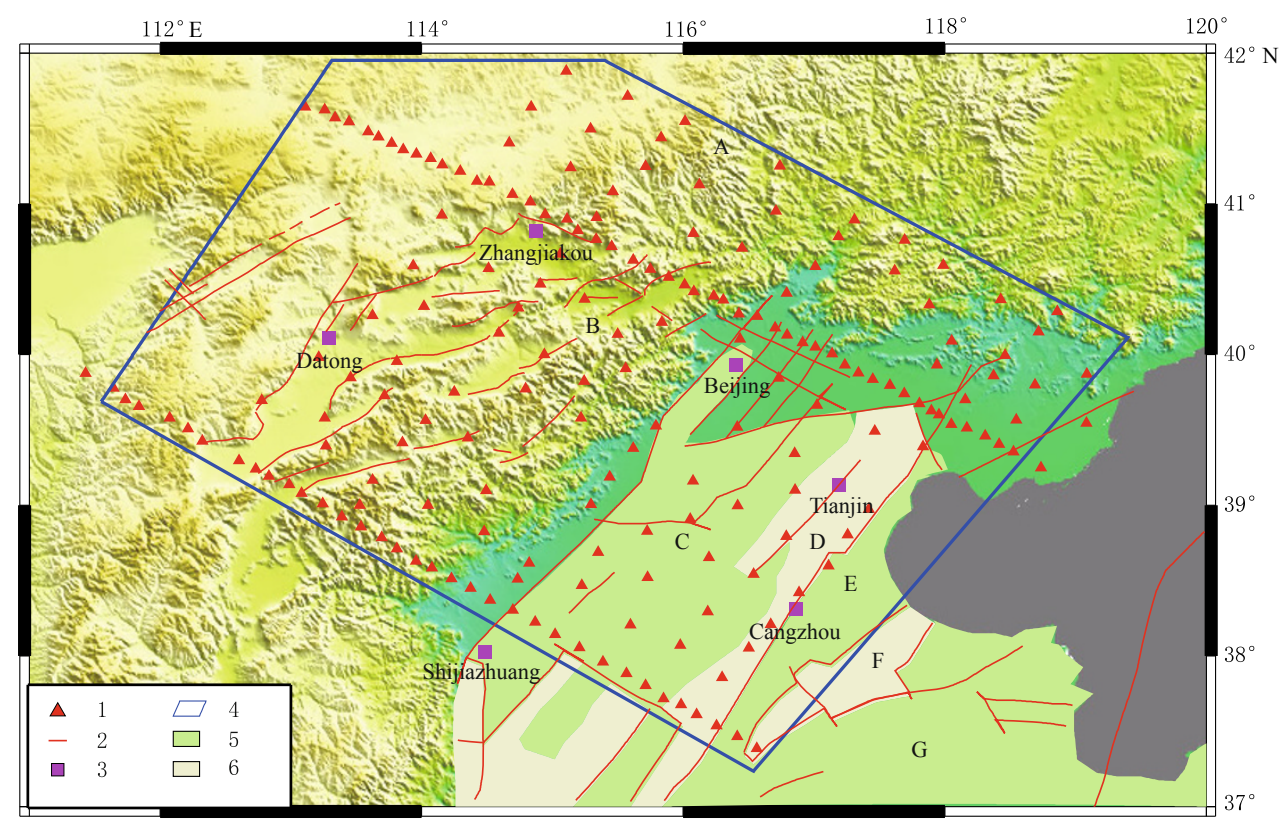

Figure 1 The tectonic sketch map and the distribution of stations. 1. Broadband stations; 2. Major active faults; 3. Cities; 4. The study region; 5. Depression in basins; 6. Uplift in basins. A.Yanshan uplift; B. Taihangshan uplift; C. Jizhong depression; D. Cangzhou uplift; E. Huanghua depression; F. Chengning uplift; G. Jiyang depression.

\section{Method}

\subsection{Estimated Green's functions from noise cross-correlation}

The exclusive use of vertical component data implies that the cross-correlations obtained by us only contain Rayleigh wave signals. The data processing procedure applied here is similar to that described in detail by Bensen et al. (2007). To avoid the redundancy we only summarize our data processing briefly as follows.

We obtained the estimated Green's functions from ambient noise cross correlation. Continuous data were pre-processed before correlation and stacking. Single station processing began by removal of the mean, trend and bandpass filtering at 4-50 s from each daily record after being decimated to $1 \mathrm{~Hz}$. It's not necessary to remove the instrumental response because the seismometers used in our study were identical with each other. When a record was missed for some instrumental problems, zero value of data was added to synchronize the clock. In order to reduce the influence of earthquake signals and instrumental irregularities from the timeseries prior to cross correlation, time domain normalization was performed by using the running-absolute-mean method.

After the time-series had been processed for each day, cross correlations were computed daily and stacked over all time periods (about 27 months). We also applied the spectral whitening in the frequency domain, to flatten the amplitude spectrum of the ambient noise in the period band of interest. For containing Rayleigh wave signals coming from opposite directions along the two-station path, the resulting cross correlations was often asymmetric with respect to the positive and the negative lags due to the inhomogeneous distribution of ambient noise sources. By averaging the positive and the negative lags of the correlation, we used the symmetric component of the correlation as the estimated Green's function. Then signal-to-noise ratios (SNR) of each Green's function were calculated and only the functions with reasonable SNR (SNR $>15)$ were used for further analysis. SNR is defined as the ratio of the peak amplitude within a time window containing the surface wave signal to the root mean square of the noise trailing the signal arrival window. Figure 2 shows part of the Green's functions with distance from 150 to 500 $\mathrm{km}$. Although Rayleigh waves are dominant in Figure 2 , there is considerable energy showing up outside the window of surface waves. This noisy energy is probably due to the strong seismic activity in the study area, whose effect could not be completely eliminated even after normalization processes (Zheng et al., 2010). 


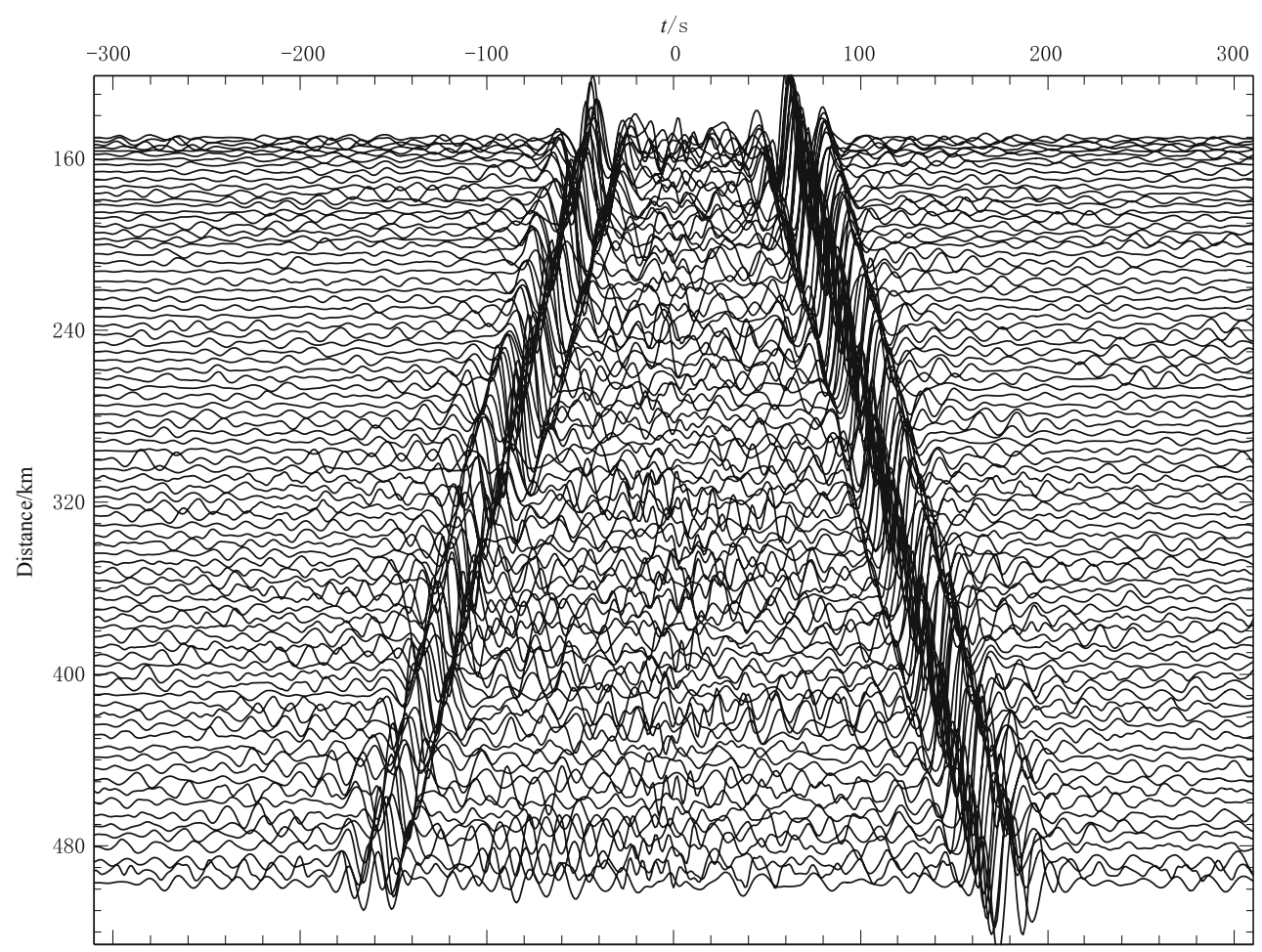

Figure 2 Stacked cross-correlations after being bandpass filtered (10-40 s) are plotted as a function of distance and time. Both positive (causal) and negative (acausal) lags are shown. To prevent the plot from being too dark and messy, only a small number of correlations with SNR greater than 25 are plotted in each distance interval.

\subsection{Measurements of Rayleigh wave phase ve- locities}

We measured the phase velocity dispersion curves of the fundamental Rayleigh wave from the estimated Green's functions by the frequency-time analysis (FTAN) technique, which is based on the continuous wavelet transformation (Wu et al., 2009). Wavelet analysis, also known as multi-resolution analysis, uses a series of dilated and delayed oscillatory functions to decompose a time-varying signal into its nonstationary spectral components. There are two key advantages of wavelet analysis over traditional Fourier analysis and windowed Fourier methods, one is that the wavelet analysis retains information on how the spectral content varies with time delay, and another is that the accuracy of the time and frequency remain constant over the entire time-frequency domain (see detail in $\mathrm{Wu}$ et al., 2009).

We can obtain the travel time $t$ for the central period $T_{0}$ according to the FTAN analysis introduced above. As being described by Yao et al. (2006), the phase velocity $c_{A B}$ at frequency. $\omega$ can be calculated by

$$
c_{A B}\left(T_{0}\right)=\frac{\Delta}{t-\frac{T_{0}}{8}},
$$

where $T_{0}=2 \pi / \omega$ is the corresponding period, $\Delta$ is the inter-station distance.

We used cubic-spline interpolation to transform cross-correlation matrix to a phase velocity versus period image and applied an automatic pick technique when extracting dispersion curves (Yao et al., 2004, 2005). The dispersion curves can be easily identified and automatically picked when start point and end point of the branch are given, and this technique greatly enhances the efficiency and reliability of phase velocity measurements. All measurements were performed manually one by one.

\subsection{Data selection}

For $N$ stations there are $N(N-1) / 2$ interstation paths, but not all paths can be used to obtain a high quality dispersion curve. In order to get a reliable tomography result, we used four criteria, which were minimum interstation distance $(3 \lambda)$, reasonable SNR, cluster analysis and travel time residual, to identify and discard bad measurements.

Firstly, the distance between two stations must be greater than three wavelengths to ensure that full surface wave packets can be separated from precursory noise and interpreted as far-field measurements (Tsai 
and Moschetti, 2010).

Secondly, only cross correlations with SNR $\geq 15$ are measured, as described before.

Thirdly, clustering measurements obtained at a particular station from a set of earthquakes located near to one another is commonly used to assess uncertainties in earthquake dispersion measurements (e.g., Ritzwoller and Levshin, 1998). A similar cluster analysis can be applied to ambient noise data. We selected dispersion curves of those ray paths with similar azimuths and similar distance to one particular station. Because of almost sampling in the same area, beneath which assuming there is not great lateral variations of $\mathrm{S}$ wave velocities, these dispersion curves are considered to be very similar to each other, and the very different one is dubious dispersion curve and should be discarded. By using clustering analysis, we can verify the reliability of measurements and discard the dubious ones.

Actually, the fourth criterion was performed during the inversion step. When a solution for phase velocity variations was obtained, remaining travel time residuals were calculated along all paths simultaneously. Some of their value may be large due to measurement errors and other factors, and this kind of data was unreasonable and should be discarded. In this study, only the data with remaining residual less than $3 \sigma$ were accepted $(\sigma$ is the initial travel time residual), and the procedure of tomographic reconstruction was repeated. Such selection of the data was performed several times until all residuals were small in the data set.

\subsection{Tomographic inversion}

In this study, a generalized 2-D linear inversion method developed by Ditmar and Yanovskaya (1987) and Yanovskaya and Ditmar (1990) has been applied to construct the phase velocity maps. As a widely used procedure (e.g., Wu and Levshin 1994; Wu et al., 1997; Ritzwoller and Levshin 1998; He et al., 2009; Fang et al., 2010; Li et al., 2012), this method is a generalization of the classical 1-D inversion method of Backus and Gilbert (1968) for 2-D problems. The inversion is performed for all interest periods $(5,10,20,30 \mathrm{~s})$ one by one. We usually take the average of phase velocity model as the starting model for each period. Taking into account incompleteness and inaccuracy of the data set, we look for a smooth image $m(r)$ of the real velocity perturbations relative to the starting model. Finally, it is possible to state the problem of searching for a solution as finding the minimum of the following function,

$$
\Psi\left(C_{\mathrm{e}}\right)=(\delta t-G m)^{\mathrm{T}}(\delta t-G m)+\alpha \iint|\nabla m(r)|^{2} \mathrm{~d} r,
$$

where,

$$
\begin{gathered}
m(r)=\left(C_{\mathrm{e}}^{-1}(r)-C_{0}^{-1}\right) C_{0} \\
\delta t_{i}=t_{i}-t_{i 0} \\
(G m)_{i}=\iint G_{i}(r) m(r) \mathrm{d} r=\int_{l_{0 i}} m(r) / C_{0} \mathrm{~d} s \\
\iint G_{i}(r) \mathrm{d} r=\int_{l_{0 i}} 1 / C_{0} \mathrm{~d} s=t_{i 0},
\end{gathered}
$$

where $r=(\theta, \varphi)$ is the position vector, $C_{\mathrm{e}}(r)$ is the predicted distribution of phase velocities, $C_{0}$ is the initial phase velocity. $t_{i}$ is the observed travel time along the $i$ th path, $t_{i 0}$ is the travel time calculated for the starting model, $l_{0 i}$ is the length of the $i$ th path and $s$ is the segment along which the inversion is performed. $\alpha$ is a regularization parameter, which is very importan$\mathrm{t}$ and controls the trade-off between fitting the travel time and smoothing the resulting maps. We conducted several tomographic maps with many different regularization parameters, e.g., $\alpha=0.02,0.05,0.1$ and 0.2 . We preferred to use the value of $\alpha=0.2$, which gave relatively smooth maps with small solution errors.

\section{Results}

Our data selection criteria result in a total number of 3667 phase velocity dispersion curves of fundamental Rayleigh wave at periods from $5 \mathrm{~s}$ to $30 \mathrm{~s}$. Figure 3 shows the distribution of these paths. Figure 4 shows corresponding number of paths at different periods, even the least number exceeds 1000 at period of $30 \mathrm{~s}$. Obviously, there is a dense and homogenous coverage of paths in the study region, and this provide a very good precondition for the high-resolution surface wave tomography.

To study the characteristic of dispersion curves between different blocks of NCC, we collected dispersion curves entirely through the central NCC and eastern NCC, respectively. Finally, we obtained 970 dispersion curves in the central $\mathrm{NCC}$ and 386 dispersion curves in the eastern NCC. Then we calculated the average dispersion curve for these two blocks, respectively, and made a comparison with AK135 model (Figure 5). It shows that phase velocities in the eastern $\mathrm{NCC}$ are faster than that in the central NCC at shorter periods (e.g. $5-10 \mathrm{~s}$ ), while it becomes a contrary situation at longer periods (e.g., 20-30 s). Additionally, dispersion curves through the eastern NCC have greater errors than that through the central NCC, indicating that speed of dispersion curves through the eastern NCC have bigger changes. Phase velocities in both the NCC blocks are slower than that for the typical global continent model (e.g. AK135 model). 


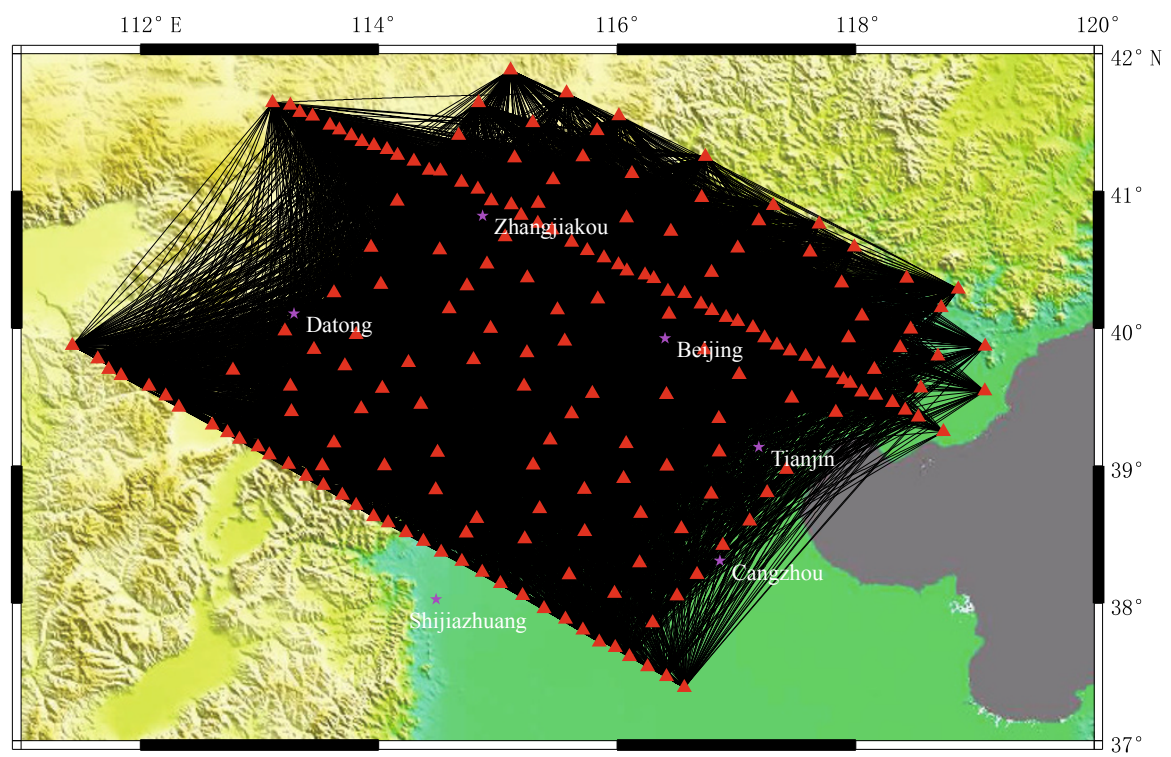

Figure 3 Distribution of Rayleigh wave rays path. Red triangles denote stations and purple-red stars denote cities.

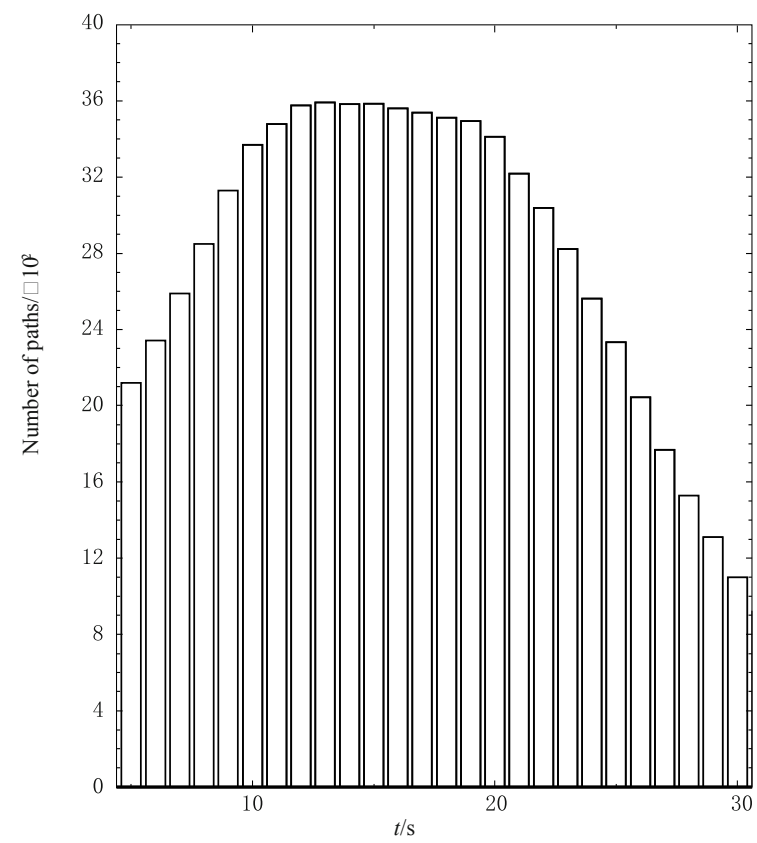

Figure 4 Number of paths at different periods from $5 \mathrm{~s}$ to $30 \mathrm{~s}$.

We performed checkerboard tests to validate the tomographic results (Figure 6 ). The study region was divided by $0.25^{\circ} \times 0.25^{\circ}$ and a velocity perturbation of $\pm 0.3 \mathrm{~km} / \mathrm{s}$ with respect to the average phase velocity for each examined period was assumed for the blocks. The test results show that the input model is well recovered at each period, suggesting that the resolution is quite good in most parts of the study area, indicating

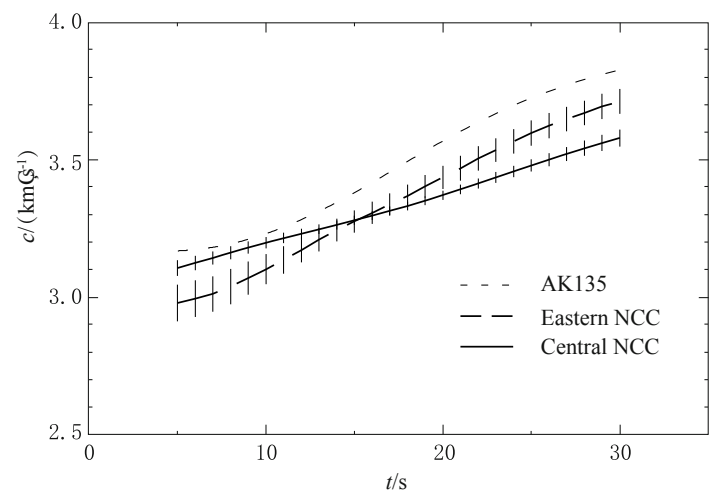

Figure 5 Average dispersion curves through the eastern NCC, central NCC and for the AK135 model.

it is reasonable to divide the study region into $0.25^{\circ} \times 0.25^{\circ}$ grids and the horizontal resolution of the phase velocity maps is $\sim 25 \mathrm{~km}$ in much of the study region.

\section{Discussion and conclusions}

In this section we analyzed the obtained phase velocity maps in terms of the geologic and tectonic features of the study region. Using the tomographic inversion method as described in the previous section, Rayleigh wave phase velocity maps at 5, 10, 20, and 30 s have been presented (Figure 7). Overall, similar lowand high-velocity features are observed at phase velocity maps (10-30 s) from teleseismic array methods (e.g., He et al., 2009; Pan et al., 2011). However, the phase 
velocities arise from CSWT are about 1-3 percent higher than those from ANT. The discrepancies have been reported by Yao et al. (2006) for Tibet and several pos- sible factors that contribute to these discrepancies are discussed (in detail see Yao et al., 2006).
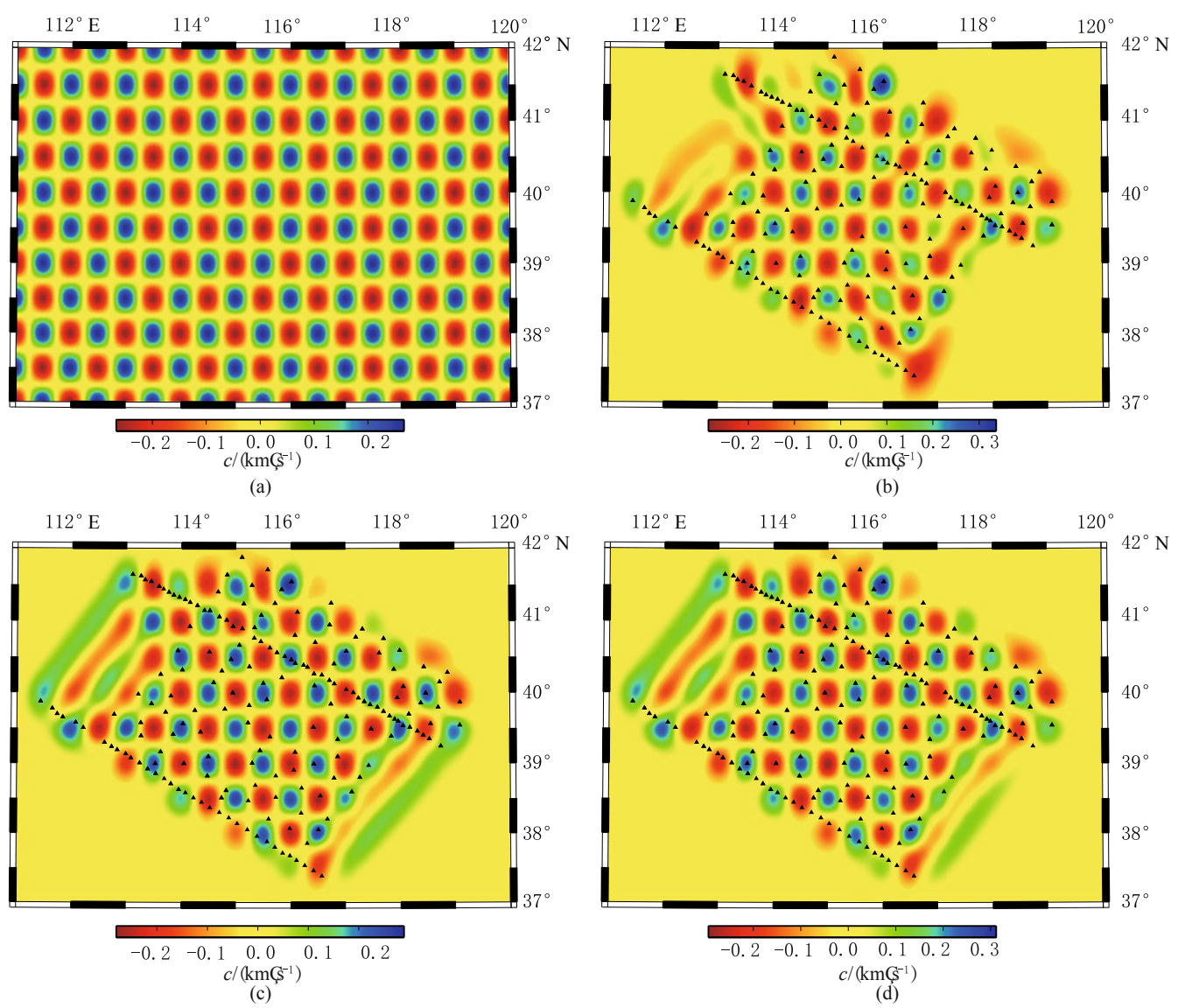

Figure 6 Checkboard test. (a) Input $0.25^{\circ} \times 0.25^{\circ}$ model; (b) Recovery of $0.25^{\circ} \times 0.25^{\circ}$ model for the path coverage at $T=5 \mathrm{~s}$. Black triangles denote the stations; (c) Recovery of $0.25^{\circ} \times 0.25^{\circ}$ model for the path coverage at $T=10 \mathrm{~s}$; (d) Recovery of $0.25^{\circ} \times 0.25^{\circ}$ model for the path coverage at $T=30 \mathrm{~s}$.

Surface waves at different periods are sensitive to seismic shear wave speeds at different depths. It is evident that the sampling depth of Rayleigh waves increases with period. In order to guide the interpretation, the sensitivity kernels of Rayleigh wave phase velocity were calculated. The 1-D $v_{\mathrm{S}}$ model used in the calculation is from the previous studies of $\mathrm{Li}$ et al. (2009).

The maps at shorter periods (e.g., $5-10 \mathrm{~s}$, Figures $7 \mathrm{a}$ and $7 \mathrm{~b}$ ) are primarily influenced by the upper crust and these velocity maps are well correlated with the major surface geological features in the study area. This is consistent with some other recent seismic studies in this region (e.g., Huang and Zhao. 2004; Tian et al., 2008; He et al., 2009; Fang et al., 2010; Pan et al., 2011). In general, higher phase velocities $(>3.15 \mathrm{~km} / \mathrm{s})$ are observed in the Taihangshan, Yanshan regions and some uplift areas (e.g., Cangzhou uplift), where Paleozoic strata and Precambrian basement rocks exposed widely on the surface. In contrast, lower velocities are observed in Quaternary intermountain basins (e.g., YanqingHuailai, Yangyuan-Yuxian) and depression zones (e.g., Jizhong, Huanghua). The major sedimentary basins and uplifts in NCB (thin lines in Figures 7a and 7b) are clearly imaged at $5-10 \mathrm{~s}$ periods with different patterns of phase velocity distribution. The deep seismic sounding (DSS) (e.g., Jia et al., 2005) and receiver function results (e.g., Luo et al., 2008) show that the sedimentary rock of NCB is about $2-8 \mathrm{~km}$ thick. The low velocities in short-period phase maps likely reflect deep sedimentary rocks in these basins. Figure 8 reveals that phase velocities at $10 \mathrm{~s}$ is very well correlated with the depth of sedimentary rocks from DSS data. Furthermore, phase 
velocity maps at $5 \mathrm{~s}$ and $10 \mathrm{~s}$ also show that the average velocities in the basins of eastern NCC block are lower than that in the basins of central NCC block, which agrees with the $\mathrm{P}$-wave arrival times tomography results, i.e., the upper crust in the eastern basins has lower velocities than that in western basins (Huang and Zhao, 2004).

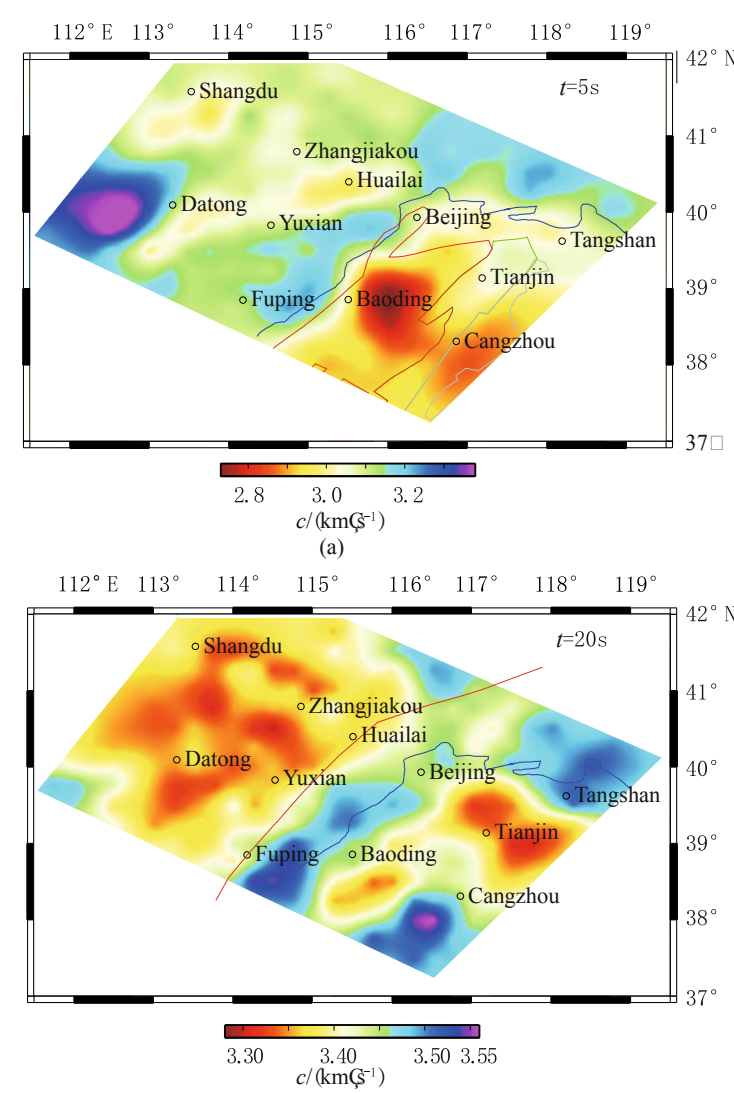

(c)
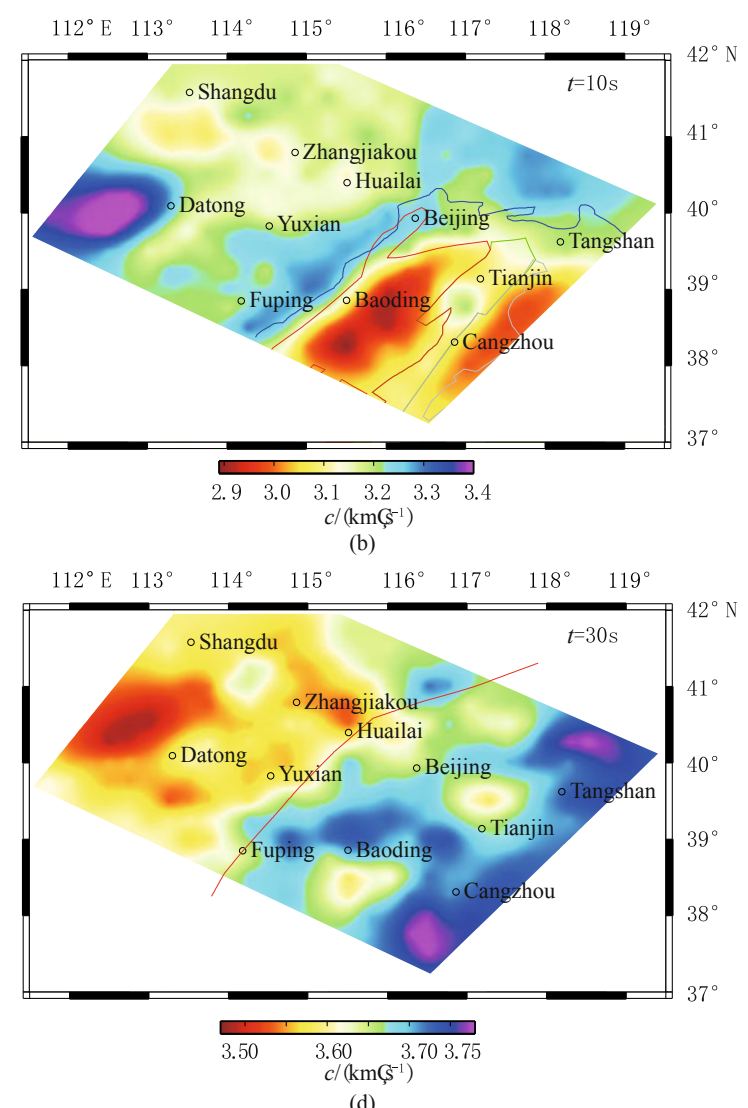

(d)

Figure 7 Rayleigh wave phase velocity maps at periods of (a) $5 \mathrm{~s}$, (b) $10 \mathrm{~s}$, (c) $20 \mathrm{~s}$, (d) $30 \mathrm{~s}$. The blue line in (a) and (b) is the topography boundary of mountains area and basins, and thin lines represent the boundaries of sub-geological units in eastern NCC. They are Jizhong depression, Cangzhou uplift and Huanghua depression from west to east, respectively. The red line in (c) and (d) is the gravity gradient belt of the Great Xingan Range-Taihang mountain.

Compared with the shorter period maps, the lowand high-velocity feature on the map of $20 \mathrm{~s}$ (Figure 7c) is very different, it shows that the average velocity in the eastern block is faster than that in the central block. The velocity distribution is in good agreement with the results of previous surface wave studies from CSWT method (e.g., Li et al., 2009; He et al., 2009; Pan et al., 2011) and body wave tomographic imaging (e.g., Tian et al., 2008). However, the velocity characteristics revealed in our maps is clearly different from that in Rayleigh wave group velocity maps (e.g., Zheng et al., 2008; Fang et al., 2010), in which they found that the average velocity in the eastern block is generally slower than that in the central block on the maps from $12 \mathrm{~s}$ to $30 \mathrm{~s}$. We believe that the sparse stations has limited resolution on different blocks within the NNCC in Zheng et al. (2008)'s study, and their map maybe only represents large-scale averages and illustrates little local detail. The velocity anomaly in different blocks of NCC revealed by our maps may related to the lower crustal composition (Li et al., 2009) that resulted from the reactivation of the NCC occurred in the Mesozoic and Cenozoic time (Qiu et al., 2005).

Moreover, low velocity anomalies are observed in the range from $20 \mathrm{~s}$ to $30 \mathrm{~s}$ nearby Tianjin and Baoding region. He et al. (2009) and Pan et al. (2011) previously imaged the low velocity anomalies near Tianjin and its adjacent region. These velocity anomalies are consis- 
tent with regional P-wave tomography (e.g., Tian et al., 2008). The low velocity anomalies in these regions are possibly associated with fluids (Huang and Zhao, 2004).

Rayleigh wave at periods (20-30 s) (Figures 7c and $7 d$ ) are principally influenced by the lower crust and uppermost mantle structure beneath the region. Overall, the low velocities are observed beneath the entire central block and the relative high velocities are observed beneath the entire eastern block of NCC from $20 \mathrm{~s}$ to $30 \mathrm{~s}$ period. The lateral variation of phase velocity in this period ranges could be mainly due to the $\mathrm{S}$ wave speed in lower crust and upper mantle, which is also associated with lateral changes in crustal depths, composition or temperature (Li et al., 2009; He et al., 2009). DSS and receiver function analysis showed that the crustal thicknesses increase gradually from $30 \mathrm{~km}$ in eastern NCC to $40 \mathrm{~km}$ in central NCC (Jia and Zhang, 2005; Luo et al., 2008). Within the period range from 20 $\mathrm{s}$ to $30 \mathrm{~s}$, high phase velocity observed in eastern NC$\mathrm{C}$ is coincident with the thin crust, whereas low phase velocities observed in central NCC with the thick crust.

In section 4, we compare the average dispersion curve respectively through the central NCC and eastern NCC. Our tomographic maps agree with the result that phase velocities in the eastern NCC are slower than that in the central NCC at shorter periods (e.g.5-10 s), while it becomes a contrary situation at longer periods (e.g., 20-30 s). It may be associated with that the eastern NCC has the more lateral and thicker sedimentary rocks, whereas thinner crustal thickness. Velocities either in central NCC or eastern NCC is obviously slower than that of AK135 model at all interest periods. These two points above are consistent with the results of the previous tomography studies of using teleseismic data (e.g., He et al., 2009, Pan et al., 2011).

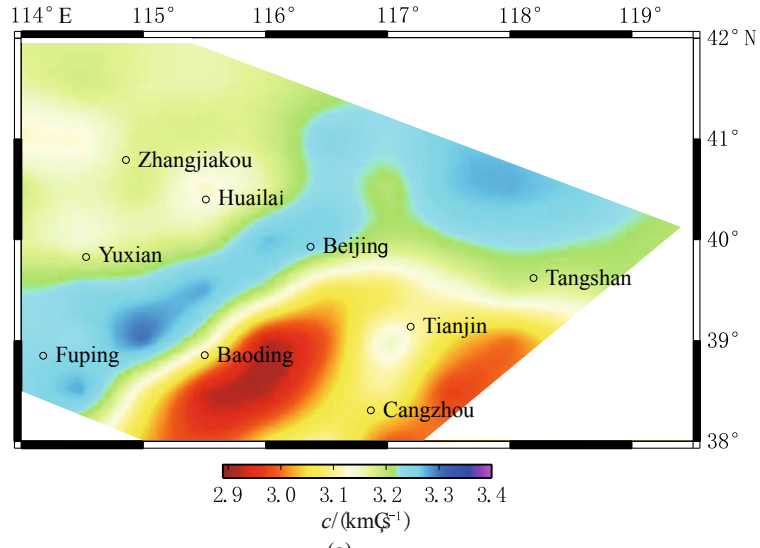

(a)

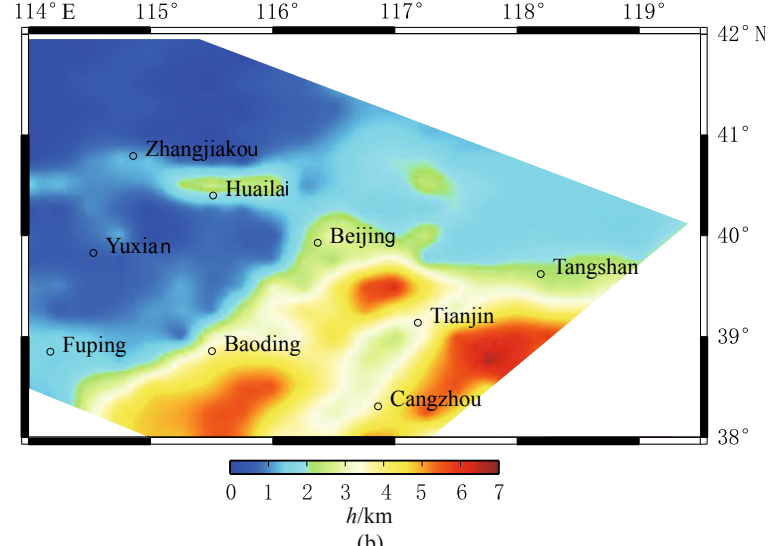

(b)

Figure 8 Phase velocity map at $T=10 \mathrm{~s}$ is compared with the distribution of the depth of sedimentary rocks in the same study region. (a) Phase velocity map at $T=10 \mathrm{~s}$ which we obtained from ANT; (b) Distribution of the depth of sedimentary rocks from DSS in the same study region (data from Jia and Zhang, 2005). Phase velocities are well correlated with the depth of sedimentary rocks, with high anomalies corresponding to shallow sedimentary rocks and low anomalies corresponding to deep sedimentary rocks.

Ambient noise surface wave tomography has been applied to data from the NCSA within the NNCC to produce high-resolution Rayleigh wave phase velocity maps. Using vertical-component time-series recorded between October 2006 and January 2008, we generate cross-correlations between all receiver pairs and measure phase velocity dispersion curves by using FTAN based on the continuous wavelet transformation method. In our study, the Rayleigh wave phase velocity maps at period from $5 \mathrm{~s}$ to $30 \mathrm{~s}$ with a resolution of $\sim 25 \mathrm{~km}$ are constructed. Because of the large number of ray paths for inversion for phase velocity maps, our velocity maps provide more detail within the central and eastern NCC than published surface wave studies. The resulting phase velocity maps at periods of $5-10$ s correlate well with the dominant surface geological features, with low-velocity anomalies corresponding to the major sedimentary basins and high-velocity anomalies coinciding with the main mountain ranges. The phase velocity maps at period from $20 \mathrm{~s}$ to $30 \mathrm{~s}$ reveal the difference of crustal thickness between central and eastern NCC block. Velocity changes are visible across Taihangshan 
Front fault in our phase maps only at period shorter than $20 \mathrm{~s}$, implying that the fault may be a crustalscale fault in this region. The low-velocity anomaly in the Beijing-Tianjin-Tangshan region displayed in the $20 \mathrm{~s}$ and $30 \mathrm{~s}$ phase maps may be associated with fluids.

Ongoing research will apply the noise crosscorrelation function (NCF) method to isotropic group velocities and Love waves, and joint inversion of the Rayleigh and Love wave dispersions that result from $\mathrm{NCF}$ and classical two-station method enable us to infer the 3-D anisotropic shear wave velocities, which may give more detailed information on the crust and uppermost mantle in this region. Joint inversion with other technique (e.g., receiver function) is also in consideration in our future work.

Acknowledgements The authors thank the anonymous reviewers for giving constructive comments that helped to improve the manuscript. We thank Prof. Yanovskaya T B for providing the surface wave tomography code. The figures were made using GMT software (Wessel and Smith, 1998). We are grateful to the colleagues of Institute of Geophysic$\mathrm{s}$, China Earthquake Administration for their help in deploying the seismic stations, collecting and preprocessing the data. This work is finacially supported by the National Natural Science Foundation of China (No.41104029), National Nonprofit Institute Research Grant of Institute of Geophysics, China Earthquake Administration (No.DQJB11B04) and Basic Research Project of Ministry of Science and Technology China (No.2006FY110100).

\section{References}

An M J, Feng M and Zhao Y (2009). Destruction of lithosphere within the north China craton inferred from surface wave tomography. Geochem Geophys Geosyst 10: Q08016, doi:10.1029/ 2009GC002562.

Backus G E and Gilbert F (1968). The resolving power of gross Earth data. Geophys J Int 16: 169-205.

Bensen G D, Ritzwoller M H, Barmin M P, Levshin A L, Lin F, Moschetti M P, Shapiro N M and Yang Y (2007). Processing seismic ambient noise data to obtain reliable broad-band surface wave dispersion measurements. Geophys J Int 169: 1 239-1 260.

Chang C (1991). Geological characteristics and distribution patterns of hydrocarbon deposits in the Bohai Bay Basin, east China. Mar Petrol Geol 8: 98-106.

Ditmar P G and Yanovskaya T B (1987). Generalization of Backus Gilbert method for estimation of lateral variations of surface wave velocities. Izv Phys Solid Earth 23:
470-477.

Fang L H, Wu J P, Ding Z F and Panza G F (2010). High resolution Rayleigh wave group velocity tomography in North China from ambient seismic noise. Geophys J Int 181: 1 171-1 182.

Griffin W L, Zhang A, O'Reilly S Y and Ryan C D (1998). Phanerozoic evolution of the lithosphere beneath the Sino-Korean Craton, in mantle dynamics and plate interactions in East Asia. In: Flower M F J, Chung A L, Lo C H and Lee T Y eds. Geodynamics Series American Geophysical Union Monograph, Washington, DC, 27: 107-126.

He Z Q, Ye T L and Ding Z F (2009). Surface wave tomography for the phase velocity in the northeastern part of North China. Chinese J Geophys 52(5): 1 233-1 242 (in Chinese with English abstract).

Huang J L and Zhao D P (2004). Crustal heterogeneity and seismotectonics of the region around Beijing. Tectonophysics 385: 159-180.

Huang Z X, Li H Y, Zheng Y J and Peng Y J (2009). The lithosphere of North China Craton from surface wave tomography. Earth Planet Sci Lett 288: 164-173.

Jia S X and Zhang X K (2005). Crustal structure and comparison of different tectonic blocks in North China. Chinese J Geophys 48(3): 611-620 (in Chinese with English abstract).

Li Y H, Wu Q J, Zhang R Q, Pan J T, Zhang F X and Zeng R S (2009). The lithospheric thinning of the North China Craton inferred from Rayleigh waves inversion. Geophys $J$ Int 177: 1 334-1 342.

Li Y H, Wu Q J, Pan J T and Sun Lian (2012). S-wave velocity structure of northeastern China from joint inversion of Rayleigh wave phase and group velocities. Geophys $J$ Int 190: 105-115.

Lin F C, Ritwoller M H, Townend J, Bannister S and Savage M K (2007). Ambient noise Rayleigh wave tomography of New Zealand. Geophys J Int 170: 649-666.

Luo Y, Chong J J, Ni S D, Chen Q F and Chen Y (2008). Moho depth and sedimentary thickness in Capital region. Chinese J Geophys 51(4): 1 135-1 145 (in Chinese with English abstract).

Menzies M A and Xu Y G (1998). Geodynamics of the North China Craton, in mantle dynamics and plate interactions in East Asia. In: Flower M F J, Chung A L, Lo C H and Lee T Y eds. Geodynamics Series American Geophysical Union, Washington, DC, 27: 155-165.

Pan J T, Wu Q J, Li Y H, Zhang R Q, Zhang F X and Zhang G C (2011). Rayleigh wave tomography of the phase velocity in the North China. Chinese $J$ Geophys 54(1): 67-76 (in Chinese with English abstract).

Qiu R Z, Deng J F, Zhou S, Li J F, Xiao Q H, Wu Z X and Liu C (2005). Lithosphere types in North China: Evidence from geology and geophysics. Sci China (Series D) 48(11): 1 809-1 827 . 
Ritzwoller M H and Levshin A L (1998). Eurasian surface wave tomography: Group velocities. J Geophys Res 103: $4839-4878$.

Sabra K G, Gerstoft P, Roux P, Kuperman W A and Fehler M C (2005). Surface wave tomography from microseism$\mathrm{s}$ in Southern California. Geophys Res Lett 32: L14311, doi: 10.1029/2005GL023155.

Shapiro N M, Campillo M, Stehly L, Ritzwoller M H (2005). High resolution surface wave tomography from ambient noise. Science 307: 1 615-1 618.

Tian Y, Zhao D P and Sun R M (2008). Seismic imaging of the crust and upper mantle beneath the North China Craton. Phys Earth Planet Int 172: 169-182.

Tsai V C and Moschetti M P (2010). An explicit relationship between time-domain noise correlation and spatial autocorrelation (SPAC) results. Geophys J Int 182: 454-460.

Wu F T and Levshin A L (1994). Surface wave tomography of East Asia. Phys Earth Planet Int 84: 59-77.

Wu F T, Levshin A L and Kozhevnikov V M (1997). Rayleigh wave group velocity tomography of siberia, China and the vicinity. Pure Appl Geophys 149: 447-473.

Wu Q J, Zheng X F, Pan J T, Zhang F X and Zhang G C (2009). Measurement of interstation phase velocity by wavelet transformation. Earthq Sci 22(4): 425-429.

Xu Y G (2001). Thermo-tectonic destruction of the Archean lithospheric keel beneath eastern China: Evidence, timing, and mechanism. Phys Chem Earth 26A: 747-757.

Yanovskaya T B and Ditmar P G (1990). Smoothness criteria in surface wave tomography. Geophys $J$ Int 102: 63-72.

Yao H J, Xu G M, Xiao X and Zhu L B (2004). A quick tracing method based on image analysis technique for the determination of dual stations phase velocities dispersion curve of surfacewave. Seism Geomagn Obs Res 25: 1-8 (in Chinese with English abstract).

Yao H J, Xu G M, Zhu L B and Xiao X (2005). Mantle structure from inter-station Rayleigh wave dispersion and its tectonic implication in western China and neighboring regions. Phys Earth Planet Int 148: 39-54.

Yao H, Van der Hilst R D and De Hoop M V (2006). Surfacewave array tomography in SE Tibet from ambient seismic noise and two-station analysis: I-Phase velocity maps. Geophys J Int 166: 732-744.

Yang Y J, Ritzwoller M H, Levshin A L and Shapiro N M (2007). Ambient noise Rayleigh wave tomography across Europe. Geophys J Int 168: 259-274.

Zhao G C, Cawood P A, Wilde S A, Sun M and Lu L Z (2000). Metamorphism of basement rocks in the Central Zone of the North China Craton: Implications for Paleoproterozoic tectonic evolution. Precambr Res 103: 55-88.

Zhao G C, Sun M, Wilde S A and Li S Z (2005). Late Archean to Paleoproterozoic evolution of the North China Craton: Key issues revisited. Precambr Res 136: 177202.

Zheng S H, Sun X L, Song X D, Yang Y J and Ritzwoller M $\mathrm{H}$ (2008). Suface wave tomography of china from ambient seismic noise correlation. Geochem Geophys Geosyst 9: Q05020, doi:10.1029/2008 GC001981.

Zheng X F, Jiao W J, Zhang C H and Wang L S (2010). Short-period rayleigh-wave group velocity tomography through ambient noise cross- correlation in Xinjiang, Northwest China. Bull Seismol Soc Am 100: 1 350-1 355.

Zheng Y, Shen W S, Zhou L Q, Yang Y J, Xie Z J and Ritzwoller M H (2011). Crust and uppermost mantle beneath the North China Craton, northeastern China, and the Sea of Japan from ambient noise tomography. J Geophys Res 116: B12312, doi: 10.1029/2011JB008637.

Zhou L Q, Xie J Y, Shen W S, Zheng Y, Yang Y J, Shi H $\mathrm{X}$ and Ritzwoller M H (2012). The structure of the crust and uppermost mantle beneath South China from ambient noise and earthquake tomography. Geophys $J$ Int doi:10.1111/j.1365-246X.2012.05423.x. 